\title{
The impact of red tape on citizen satisfaction: An experimental
}

\author{
study \\ Accepted for the International Public Management Journal \\ Lars Tummers*, Ulrike Weske**, Robin Bouwman*** \& Stephan Grimmelikhuijsen** \\ * Department of Public Administration, Erasmus University Rotterdam \& Center for the \\ Study of Law \& Society, University of California, Berkeley \\ ** Utrecht School of Governance, Utrecht University \\ *** Public Administration, Institute for Management Research, Radboud University \\ Nijmegen \\ Tummers@fsw.eur.nl, u.weske@uu.nl, r.bouwman@fm.ru.nl, s.g.grimmelikhuijsen@uu.nl
}

To be cited as:

Tummers, L.G., Weske, U., Bouwman, R. \& Grimmelikhuijsen, S.G. (2015) The impact of red tape on citizen satisfaction: An experimental study. International Public

Management Journal

Acknowledgement: We would like to thank the editor-in-chief (Prof. Steve Kelman) and the anonymous referees for their constructive comments on earlier versions of this article. 


\title{
RED TAPE AND CITIZEN SATISFACTION
}

\begin{abstract}
Red tape is one of the most often-mentioned nuisances of citizens about government. However, there is a dearth in red tape research focusing on citizens. Therefore, the primary goal of this article is to analyze the effect of red tape on citizen satisfaction. The secondary goal is to go beyond testing a linear relationship between red tape and citizen satisfaction by examining individual factors that may moderate this relationship. In order to analyze the red tape-satisfaction relationship, we have designed an experiment in which 179 subjects participated. Experiments are still relatively rare in public administration, but are increasingly seen as a rigorous and useful method for theory testing and development. We found that red tape has a strong negative effect on citizen satisfaction, and that this effect is weaker when citizens have high knowledge of political processes. We conclude with implications and a future research agenda.
\end{abstract}

\section{KEYWORDS}

Red tape; citizen satisfaction; rules; behavioral public administration; experimental method 


\section{INTRODUCTION}

The concept of red tape has received a great deal of attention in public management research (Bozeman and Feeney 2011; Pandey and Scott 2002). In its most general form, red tape is defined as "rules, regulations and procedures that entail a compliance burden without advancing the legitimate purposes they were intended to serve" (Bozeman 2000, 12). In other words, these rules are burdensome, while providing no added value.

Within the red tape research field, much attention has focused on organizational red tape, emphasizing red tape burdens for employees, often public managers themselves (e.g., Walker and Brewer 2008; DeHart-Davis and Pandey 2005; Feeney and DeHartDavis 2009; Moynihan, Wright and Pandey 2012). The concept of organizational red tape remains an important focal point of red tape research, but public managers are only one of the many stakeholders who can experience red tape. Another internal stakeholder group is for instance street-level bureaucrats, while external stakeholders include politicians, other public organizations and private suppliers.

In this study, we will analyze the effects of red tape on one specific group of external stakeholders: citizens. Citizens - having often been neglected in red tape research - are a crucial stakeholder group for many public organizations. Citizens can also experience red tape (Walker and Brewer 2008). For instance, when applying for a building permit to construct an additional room or dormer for their house, citizens can be confronted with various burdensome governmental rules they have to follow. However, red tape researchers have up to now largely neglected stakeholder red tape and especially red tape for citizens (Brewer and Walker 2010b, 248). Citizens are important because of 
the legitimacy they provide to government organizations. Without citizen support, the functioning and ultimately the existence of public organizations are threatened (Easton 1975; Vigoda 2002). Citizens are also important because of their sheer numbers: public organizations have to deal with many citizens, directly (through service provision) or indirectly (through public opinion). Lastly, red tape is one of the most often-mentioned nuisances citizens experience about government (Gore 1993) and many government reforms have therefore focused on reducing red tape for citizens to improve citizen attitudes toward government (Pollitt and Bouckaert 2004). Cross-sectional surveys have shown that red tape does indeed correlate with citizen attitudes and specifically citizen satisfaction (Townsend and Kosloski 2002). However, these studies only prove correlations, and no causal relations between red tape and satisfaction. In conclusion, the importance of red tape for this large stakeholder group can hardly be overstated, but there is a dearth in red tape research about the effect of red tape on this group.

The primary goal of this article is to investigate the effect of red tape on citizen satisfaction. The secondary goal is to go beyond testing a linear relationship between red tape and citizen satisfaction by examining individual factors that may moderate this relationship. Social psychology teaches us that attitudinal changes through information processing are affected by situational and dispositional factors (Bohner 2001). Similarly, Pandey and Kingsley $(2000,783)$ argue that "one is hard pressed to find serious students of red tape who do not, at some point or another, stress the importance of studying the individual in order to gain a better understanding of red tape." Hence, we should analyze whether certain individual characteristics influence the relationship between red tape and 


\section{RED TAPE AND CITIZEN SATISFACTION}

citizen satisfaction. In order to provide a better explanation for the link between red tape and citizen satisfaction, we chose for two possible important moderating variables, one more situation-based (knowledge of politics) and one dispositional (emotional reactance to rules) (Grimmelikhuijsen and Meijer 2014; Shen and Dillard 2005). Based on the above, we have formulated the following research question:

To what extent does red tape influence citizen satisfaction, and to what extent is this relationship influenced by citizens' knowledge of politics and/or emotional reactance to rules?

In order to study red tape experienced by citizens, we have designed an experiment in which 179 subjects participated. When testing for causal effects, few of the methods in the social sciences can live up to the rigor and level of control of an experimental design. Experiments are still relatively rare in public administration, but are increasingly seen as a rigorous and useful method for theory testing and development (Margetts 2011; Baethge et al. 2015).

Experiments can also benefit red tape research, which has been dominated by cross-sectional designs (Bozeman 2012). A few important and well-executed experiments on red tape have been conducted (Scott and Pandey 2000; Kaufmann and Feeney 2014), but not on the effects of red tape on citizen attitudes. Based on our experiment we conclude that red tape has a negative effect on citizen satisfaction, and that this effect is 
weaker when citizens have high knowledge of political processes. Citizen emotional reactance does not moderate this relationship.

\section{THEORETICAL FRAMEWORK}

The Background of Red tape

The term "red tape" stems from the sixteenth-century, when the government of Henry VIII of England (1491-1547) started to produce proclamations that were written on scrolled pieces of paper, tied with red tape (Bozeman and Feeney 2011, 20). The recipients of these scrolls began to use the term red tape to refer to complex and burdensome government rules.

Scholarly interest in red tape is more recent. One of the first scholars to study red tape systematically was Herbert Kaufman, who published "Red Tape, Its Origins, Uses, and Abuses" in 1977. Although the work of Kaufman is influential, it has not been used extensively for empirical research, among other things because it is very hard to operationalize (Bozeman 2012). Kaufman asks the question "How much red tape should you tolerate to get satisfying amounts of what you want?" Kaufman viewed red tape mainly originating from outside the organization as a product of intensive external control and large numbers of diverse stakeholders. He noted that "one person's red tape is another's treasured procedural safeguard" $(1977,4)$. This resembles Waldo's observation that “one man's red tape is another man's system” (1946, 369 in Brewer and Walker 2010b, 248). Hence, red tape can be beneficial for some people. 
By contrast, another, and in public administration more prevalent, view on red tape sees red tape as a pathology. The notion that red tape may be "beneficial" is strongly rejected. This line of reasoning mainly builds on the work of Bozeman (E.g., Bozeman 1993, 2000, Bozeman and Feeney 2011), who notes that (1993, 275): "In common usage, red tape has a strongly negative tenor and most laymen would, in all likelihood, be unable to make much sense of the notion of beneficial red tape." He also cited Goodman (1987, 63) who notes that red tape is one of "most enduring and universal rejection symbols in the English language."

In this article, we follow the line of reasoning that red tape is a pathology (see also, for instance, Moon and Bretschneider 2002; Pandey and Kingsley 2000; Pandey and Marlowe 2014). A rule or procedure will likely be perceived by an actor as red tape if it is unclear for that actor what benefits it entails. Red tape is then defined as "rules, regulations and procedures that entail a compliance burden without advancing the legitimate purposes they were intended to serve" (Bozeman 2000, 12). The idea that red tape is inherently negative makes it different from three adjacent concepts: green tape, formalization and administrative burden. "Green tape" is a more positive perspective on rules, and research from this perspective focuses on what makes rules effective, as opposed to what makes them ineffective (DeHart-Davis 2009; De Hart-Davis, Chen and Little 2013). The second neighboring concept is formalization. Formalization can be defined as "the extent to which rules, procedures, instruction and communications are written" (Pugh, Hickson and Hinings 1969, 75). This means that formalization is a concept that is more neutral than red tape and green tape. Formalization therefore shares 
some ground with red tape (and green tape for that matter), as written rules or procedures can either be a pathology (red) or effective (green). Lastly, in a recent article Moynihan, Herd and Harvey (2014) distinguish administrative burden from red tape, noting that red tape is inherently bad, whereas administrative burdens serve a legitimate purpose and are not inherently bad. We specifically focus on red tape because of its centrality in the public administration debate and the idea that red tape is a common nuisance of citizens.

\section{The Effects of Red tape}

The literature on (especially organizational) red tape overwhelmingly points out its negative effects on several organizational and individual variables. For instance, studies have shown the detrimental impacts of red tape on organizational performance (e.g., Brewer and Selden 2000; Pandey, Coursey and Moynihan 2007; Brewer and Walker 2010b). Furthermore, red tape has been shown to lead to a reduction in benefits provided to clients (Scott and Pandey 2000), a more risk-averse organizational culture (Bozeman and Kingsley 1998; Feeney and DeHart-Davis 2009), and reduced innovative and productive potential of organizations (Bozeman and Kingsley 1998; DeHart-Davis and Pandey 2005). On the individual level, higher perceived red tape is related to increased intention to leave (Giauque, Ritz, Varone and Anderfuhren-Biget 2012), decreased organizational commitment (Stazyk, Pandey and Wright 2011; DeHart-Davis and Pandey 2005) and lower Public Service Motivation (Scott and Pandey 2005).

Only a few studies focus specifically on the effects of red tape on citizen satisfaction, although related work on red tape and job satisfaction indicates a negative 


\section{RED TAPE AND CITIZEN SATISFACTION}

relationship (Boardman, Bozeman and Ponomariov 2010; DeHart-Davis and Pandey 2005). Townsend and Kosloski (2002) analyzed the relationship between red tape and citizen satisfaction, and concluded red tape was negatively related to satisfaction of clients with community-based elder care. Brewer and Walker (2010), in contrast, found that red tape does not seem to have any appreciable impact on customer satisfaction in English local government. However, Brewer and Walker measured internal and external red tape by surveying managers. Citizens might perceive the level of external red tape differently than managers do. In addition to these mixed findings, both studies rely on results from a cross-sectional survey. An experimental design could provide more insights into the causal relationship between red tape and citizen satisfaction.

The body of knowledge on red tape - even though most research has been done on other attitudinal measures and other forms of red tape - mostly points in the direction of negative effects on various attitudinal measures. Therefore, we postulate the following hypothesis:

H1: Red tape has a negative effect on citizen satisfaction.

Moderating Variables: Knowledge and Emotional Reactance In order to provide a more comprehensive explanation for the link between red tape and citizen satisfaction we introduce two moderating variables: knowledge of politics and emotional reactance to rules. 
We will firstly analyze the possible impact of knowledge of politics. Generally speaking, people process information differently if they have certain beliefs or attitudes concerning the topic. Information will be related and interpreted in terms of their preexisting knowledge (Bohner 2001). The Elaboration Likelihood Model (ELM), which was developed in the field of social psychology by Petty and Cacioppo (1986), provides a theoretical basis for this. ELM states that attitude change can take place both through effortful and effortless processing of information. The "central route" of ELM-related to effortful processing of information-proposes that people who are exposed to a persuasive message relate the message to their existing knowledge about the message topic (Bohner 2001, 253). Persuasion through the central route is a process that involves deliberative and active information processing in terms of scrutiny. The ELM also proposes a "peripheral route" based on social identification, conditioning, and the use of heuristics. This route is chosen when people spend limited time or have little knowledge to process a persuasive message.

This means that people who have limited knowledge about government can be expected to change their attitude more easily, since they cannot relate the new information to existing patterns. This means a new pattern is created because of the new experience. People who already have substantial knowledge will more quickly engage in heuristics and "peripheral" information processing.

This means that the ELM model offers important insights on the potential relation between knowledge and red tape. People who already have a great deal of knowledge about politics and government will relate their experience with red tape to this 
knowledge. As a result, they will not easily be surprised and have more stable attitudes towards government. An application of ELM in the field of public administration has been carried out by Grimmelikhuijsen and Meijer (2014). Following the same logic as proposed here, they empirically found that the attitudes of people with high levels of knowledge were not influenced by government information, whereas citizens who reported have little knowledge did change their attitude after reading government information.

This indicates that high levels of prior knowledge are expected to lessen the impact of red tape. On the other hand, if people have little knowledge they are more likely to develop new patterns to determine their attitude based on the event (i.e., red tape). Hence, they will be more influenced by the event.

Based on the above, we hypothesize that prior knowledge of politics moderates the relationship between red tape and citizen satisfaction. High levels of prior knowledge are expected to weaken this relationship (because people who know a lot about politics and governmental processes are not easily altered in their beliefs based on a single event), whereas low levels of knowledge are expected to strengthen it.

$\mathrm{H} 2$ : The impact of red tape on satisfaction is weaker for people having high knowledge of politics

Next, we analyze the potential moderating effect of a dispositional variable: emotional reactance to rules. In contrast to knowledge of politics, emotional reactance to rules can 
be seen as a personality trait, which is not easily altered. Emotional reactance to rules is a dimension of the more general concept of psychological reactance (Shen and Dillard 2005). Research involving psychological reactance - or rebelliousness - examines how people respond when their behavioral freedoms are restricted. Psychological reactance is defined as "the motivational state that is hypothesized to occur when a freedom is eliminated or threatened with elimination" (Brehm and Brehm 1981, 37). Psychological reactance can be considered as a personality trait to the extent that some individuals interpret actions as a threat to their freedom more than others (Shen and Dillard 2005). Scholars studying rebelliousness have shown that people scoring high on psychological reactance are defensive, autonomous and non-affiliative (Dowd and Wallbrown 1993). Further, psychological reactance has been found to be negatively related both to readiness to change (Holt, Armenakis, Field and Harris 2007) and willingness to implement public policies (Tummers, Steijn and Bekkers 2012).

We focus especially on one particular dimension of psychological reactance: emotional reactance to rules (or emotional response toward restricted choice). Emotional reactance is considered the first and most important factor concerning psychological reactance (Hong and Page 1989). Furthermore, it is highly related to how people respond to rules, making it salient for red tape research. Emotional reactance to rules concerns the way people respond when their freedom is restricted. People scoring high on emotional reactance become frustrated and unsatisfied when they cannot act in their own way. In other words, they more easily feel bound by rules. 


\section{RED TAPE AND CITIZEN SATISFACTION}

We expect that for people scoring higher on emotional reactance, red tape has a stronger effect on their satisfaction. In red tape situations, people are obliged to conduct extra (unnecessary) work in order to comply with governmental standards and procedures. They are increasingly coerced by government to act in certain ways, and the people scoring high on emotional reactance are inclined to react negative to such situations. This brings us to the third hypothesis:

H3: The impact of red tape on satisfaction is stronger for people scoring high on emotional reactance.

\section{DATA AND METHOD}

Setting and Context

The hypotheses were tested in a campus-based classroom experiment at two Dutch universities. A classroom setting was chosen since it allows for more experimental control. In the classroom, subjects were asked to fill out a fictitious form for a passport renewal. In the Netherlands, like in other European states, citizens can apply for a passport in the municipality where they live. A passport application procedure was chosen because it is a familiar context for a participant, which does not require much empathy or role-play. This enhances the "mundane reality" for participants in the experiment. To prevent any pre-existing perceptions or priming effects we made up a name for the fictitious municipality on the forms. 
Although the use of students as subjects for our experiment can pose challenges to external validity, Margetts (2011) notes that, theoretically, the validity of an experiment is based on the difference between the performance of randomly allocated treatment and control groups, rather than the representativeness of the subject group (see also Calder, Phillips and Tybout 1982). Furthermore, Mintz, Redd and Vedlitz (2006) suggests that students can be used when they represent citizens, as is the case in our study. This is beneficial for external validity claims. Moreover, using students has advantages for internal validity, as they are a more homogenous sample than non-student samples, which allows for better comparison between experimental groups (Morton and Williams 2010, $351)$.

\section{Design}

A basic between-group design was set up for the experiment. In this design, the independent variable (red tape) is manipulated in order to test its effect on the dependent variable (citizen satisfaction). The participants received four documents: 1) the pre-test questionnaire, 2) the fact sheet, 3) a passport application form and 4) the post-test questionnaire. Passport forms, the pre- and post-test as well as a fact sheet for participants were printed and stapled together. The process of the experiment is shown in Figure 1.

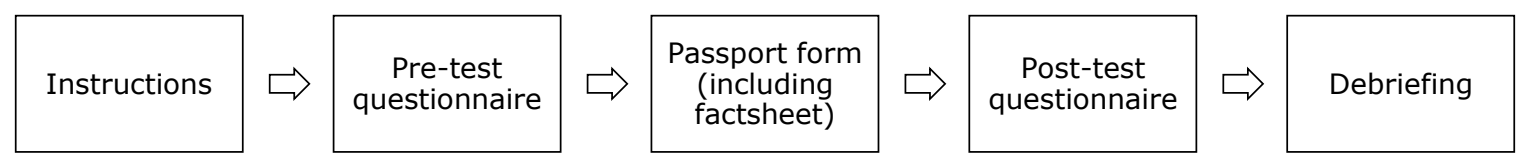

\section{Figure 1 Processes during experiment}


Passport forms (both treatment and control) were administered randomly. Further, in a brief instruction before the experiment was carried out, participants were told that participation was voluntarily. Also, we explicitly told participants the passport form itself was not needed for data analysis, so their anonymity was safeguarded. To further preserve anonymity, an additional "factsheet" was supplied to participants. This factsheet contained information that could be used in filling out the application form such as a fictitious social security number, fictitious date of birth etc. In advance, students were told that the goal of the experiment was to measure attitudes towards public service delivery. This ensured that students would understand the necessity to fill out the forms, without priming them towards the specific hypothesis and subject of this study. Finally, students were explicitly asked not to discuss or compare the forms and questionnaires during the experiment.

Two experimental passport application forms were created for the purpose of this study. The treatment form contained a high level of red tape, and the control form contained a low level of red tape. We artificially created "high" red tape by introducing burdensome rules that did not have a legitimate purpose. In doing so we followed the generally accepted definition of red tape by Bozeman (2000) and followed in the footsteps of the way red tape was manipulated in the experimental study of Scott \& Pandey (2000). The following manipulations were included. First, we asked respondents both to write down their date of birth, social security number and date of signature, and provide the same information by ticking boxes in a large computer-readable grid 
representing the numbers 0 till 9 . Such a grid is often used by (older) computer programs to read for instance scores on multiple choice exams.

The explanation provided was that this was needed for the complete and accurate processing of the form by the municipality. In previous times such grids were indeed helpful for accurately processing information. However, modern scan machines can also read numbers. This is an example of a rule-evolved red tape: a rule that initially served a useful function but later became transformed into red tape (Bozeman and Feeney 2011). Second, we asked respondents for information that is not necessary for the passport application process and does not contribute to the legitimacy objective of the procedure, and therefore not to its legitimacy. We asked for the following information: color of eyes and hair (can already be seen in the passport photo), whether the applicant is older than 18 years (in addition to asking for the date of birth), whether the applicant had travelled outside of the European Union in the past 5 years, and their motivation for applying for a passport. These are examples of rule-inception red tape: rules that are dysfunctional from the start (Bozeman and Feeney 2011). Besides the red tape manipulations, the overall design of the forms remained the same for the control and the treatment groups.

Two pilot rounds ( $\mathrm{n}=9$ and $\mathrm{n}=12$ ) were administered, which led to improvement of both the questionnaire and the passport form. Typographical errors and unclear questions were removed or adjusted, and the order of questions and general layout was improved.

The experiment was carried out in a classroom. Our subjects were aware they were participating in scientific research. Although we designed the passport procedure as 


\section{RED TAPE AND CITIZEN SATISFACTION}

realistically as possible, the fact that the procedure took place in a classroom takes away some of the realism of the experiment. Hence, students knew they were not applying for an actual passport. That said, as the classroom setting was equal for all subjects in our experiment, so this limitation had the same effect on all participants and does not affect the internal validity of the experiment.

After the instruction of approximately ten minutes the experiment started. When students had finished their forms, they were allowed to hand in their forms to one of the researchers. Students were debriefed after all forms and questionnaires were collected by the researchers. The precise purpose of the experiment was revealed and students were allowed to pose questions.

\section{Measures}

Satisfaction is generally taken to mean an "evaluative attitude towards some object or experience" (James 2009, 108). Although there is a large literature on satisfaction with private goods and services, most research conducted on satisfaction in the public sector has been undertaken by public bodies themselves and has been directed towards managerial decisions rather than addressing theoretical questions (James 2009; Van Ryzin 2004, 2006; Van Ryzin, Muzzio, Immerwahr, Gulick and Martinez 2004). As Bouckaert and van de Walle $(2003,330)$ argue, "[S]atisfaction has shown itself to be elusive to measurement and very service-specific (...). It can only be interpreted in relation to the significance of a given service." 
Based on the above, we used a service-specific operationalization of citizen satisfaction, which led to four items, shown in Table 1 (scale 1, very unsatisfied, to 10, very satisfied). As can be seen from the factor loadings, all items are highly related to the citizen satisfaction variable. Related to this, the Cronbach's alpha (.89) was adequate.

\section{Table 1 Measurement of citizen satisfaction}

\begin{tabular}{lc}
\hline Items & Factor \\
How satisfied are you... & loadings \\
\hline ...with the passport application procedure? & .870 \\
$\ldots$ with the duration of the passport application procedure? & .815 \\
$\ldots$ with this passport application procedure compared to your expectations & .886 \\
about a passport application procedure? & .909 \\
\hline
\end{tabular}

Emotional reactance was measured using the three items as suggested by the Hong Reactance Scale (Shen and Dillard 2005) (five-point Likert scale, from strongly disagree to strongly agree). One of these items was deleted due to its low correlation with the other two items. The resulting two-item scale had a reliability of .70 and adequate factor loadings, as shown in Table 2. 
RED TAPE AND CITIZEN SATISFACTION

Table 2 Measurement of emotional reactance

\begin{tabular}{lc}
\hline Items & Factor \\
& loadings \\
\hline I become frustrated when I am unable to make free and independent decisions & .842 \\
I become angry when my freedom of choice is restricted & .842 \\
\hline
\end{tabular}

Finally, knowledge of local politics was measured with two items: "How much do you know about local politics?” and "How interested are you in local politics?" (1-4 scale, from very little to a lot, Cronbach's alpha=.77 and adequate factor loadings, see Table 3). This is comparable with previous subjective measures of knowledge (e.g., Grimmelikhuijsen and Meijer 2014). We opted for subjective knowledge (what do people think they know) instead of objective knowledge (what factual knowledge do people actually possess) because the development of objective tests of a person's knowledge must be done individually for this experiment. On the other hand, subjective knowledge may be measured with a more general scale, such as the one used here. A subjective measure may thus be more feasible to use than developing a (new) objective measure. 
RED TAPE AND CITIZEN SATISFACTION

Table 3 Measurement of knowledge of politics

\begin{tabular}{lc}
\hline Items & Factor \\
& loadings \\
\hline How much do you know about local politics? & .900 \\
How interested are you in local politics? & .900 \\
\hline
\end{tabular}

Both knowledge and emotional reactance items were asked before the experimental treatment to prevent these variables from being affected by the treatment.

\section{Subject Characteristics}

Our total sample consisted of 179 public administration bachelor's students from two Dutch universities. We checked the whether the experimental groups were homogeneous on a number of criteria. The importance of homogeneity is shown by a case where the control and treatment groups are not homogeneous: if there are only males in the control group and females in the treatment group, the outcome of the experiment might not be caused by the manipulation (red tape) but by gender difference in the groups.

Some demographic variables that have been reported to affect citizen satisfaction, such as age and gender (Kusow, Wilson and Martin 1997). We also included political affiliation as a control variable, since political affiliation could affect citizen satisfaction with government.

Table 4 shows that $51 \%$ of the sample consists of females, with age averaging at 21 years and political orientation on a five-point scale from left (1) to right (5) being 3.8 


\section{RED TAPE AND CITIZEN SATISFACTION}

on average. Furthermore, the self-assessed knowledge of politics is 2.1 (on a 1-4 scale), and the degree of emotional reactance 3.5 (on a 1-5 scale).

The differences between the control and treatment group on gender, age and political orientation were all insignificant. This should cancel out confounding effects, making it unnecessary to include these background variables in in the regression analyses (Grimmelikhuijsen 2011). Furthermore, differences on the moderating variables are insignificant, which also indicates effective randomization. These variables, however, will be included, as we will analyse their individual impact on citizen satisfaction, and their moderating impacts on the relationship between red tape and citizen satisfaction, in order to test hypothesis 2 and 3. 
RED TAPE AND CITIZEN SATISFACTION

Table 4 Sample composition on background variables

\begin{tabular}{|c|c|c|c|c|c|}
\hline & $\%$ female & Average age & $\begin{array}{l}\text { Political } \\
\text { preference } \\
(1=\text { very } \\
\text { leftwing, } \\
\text { 5=very } \\
\text { rightwing) }\end{array}$ & $\begin{array}{l}\text { Knowledge } \\
\text { of politics } \\
\text { (1-4 scale) }\end{array}$ & $\begin{array}{l}\text { Emotional } \\
\text { reactance } \\
(1-5 \text { scale })\end{array}$ \\
\hline $\begin{array}{l}\text { Control } \\
\text { group (low } \\
\text { red tape) }\end{array}$ & 50.6 & 21.08 & 3.86 & 2.10 & 3.53 \\
\hline $\begin{array}{l}\text { Treatment } \\
\text { group (high } \\
\text { red tape) }\end{array}$ & 50.9 & 21.34 & 3.68 & 2.10 & 3.47 \\
\hline Mean & 50.8 & 21.22 & 3.76 & 2.10 & 3.49 \\
\hline Difference & Chi & ANOVA, & Chi & ANOVA, & ANOVA, \\
\hline tests & $\begin{array}{l}\text { Square }=.002, \\
p=.965\end{array}$ & $\begin{array}{l}\mathrm{F}=.618, \\
\mathrm{p}=.433\end{array}$ & $\begin{array}{l}\text { Square }=2.477 \\
\mathrm{p}=.649\end{array}$ & $\begin{array}{l}\mathrm{F}=.003, \\
\mathrm{p}=.959\end{array}$ & $\begin{array}{l}\mathrm{F}=.251, \\
\mathrm{p}=.617\end{array}$ \\
\hline
\end{tabular}

Manipulation Check

Before proceeding to the results, we should check whether participants perceived the experimental treatment (the manipulation) in the way we intended. In other words, we 
should perform what experimentalists call a "manipulation check": did our treatment really tap into measuring "perceived red tape"? The measure of perceived red tape was introduced by Rainey, Pandey and Bozeman (1995). Based on this, a strong tradition on measuring perceived red tape has developed (e.g., DeHart-Davis \& Pandey 2005; Moon and Bretschneider 2002; Pandey and Welch 2005; Brewer and Walker 2010a; Chen 2011; Ponomariov and Boardman 2011). We therefore used the perceived red tape measure by Rainey, Pandey and Bozeman (1995), which was applied to the situation of the passport application. It read: "If red tape is defined as burdensome administrative rules and procedures that have negative effects on the performance of this municipality, please assess the level of red tape during the passport application." We measured red tape after the questions about citizen satisfaction, thereby reducing priming effects on citizen satisfaction. An ANOVA test showed that the manipulation was successful. Participants in the control group indeed reported a significantly lower degree of red tape than participants in the treatment group $\left(M_{\text {Control }}=4.01, S D=1.9 ; M_{\text {Treatment }}=6.92, S D=1.5\right.$; $F=125.72, p<.001)$. Hence, our measure of red tape via the passport procedure fits the common measure of perceived red tape.

\section{RESULTS}

In order to assess the results, we first present Figure 2, which graphically compares the control and treatment group on their degree of citizen satisfaction. Figure 2 shows that the degree of citizen satisfaction is lower when citizens are confronted with high red tape (citizen satisfaction 4.87 vs. 6.08). This is statistically significant $(F=26.989, p<.01)$, 


\section{RED TAPE AND CITIZEN SATISFACTION}

thereby providing support for our first hypothesis: red tape negatively affects citizen satisfaction.

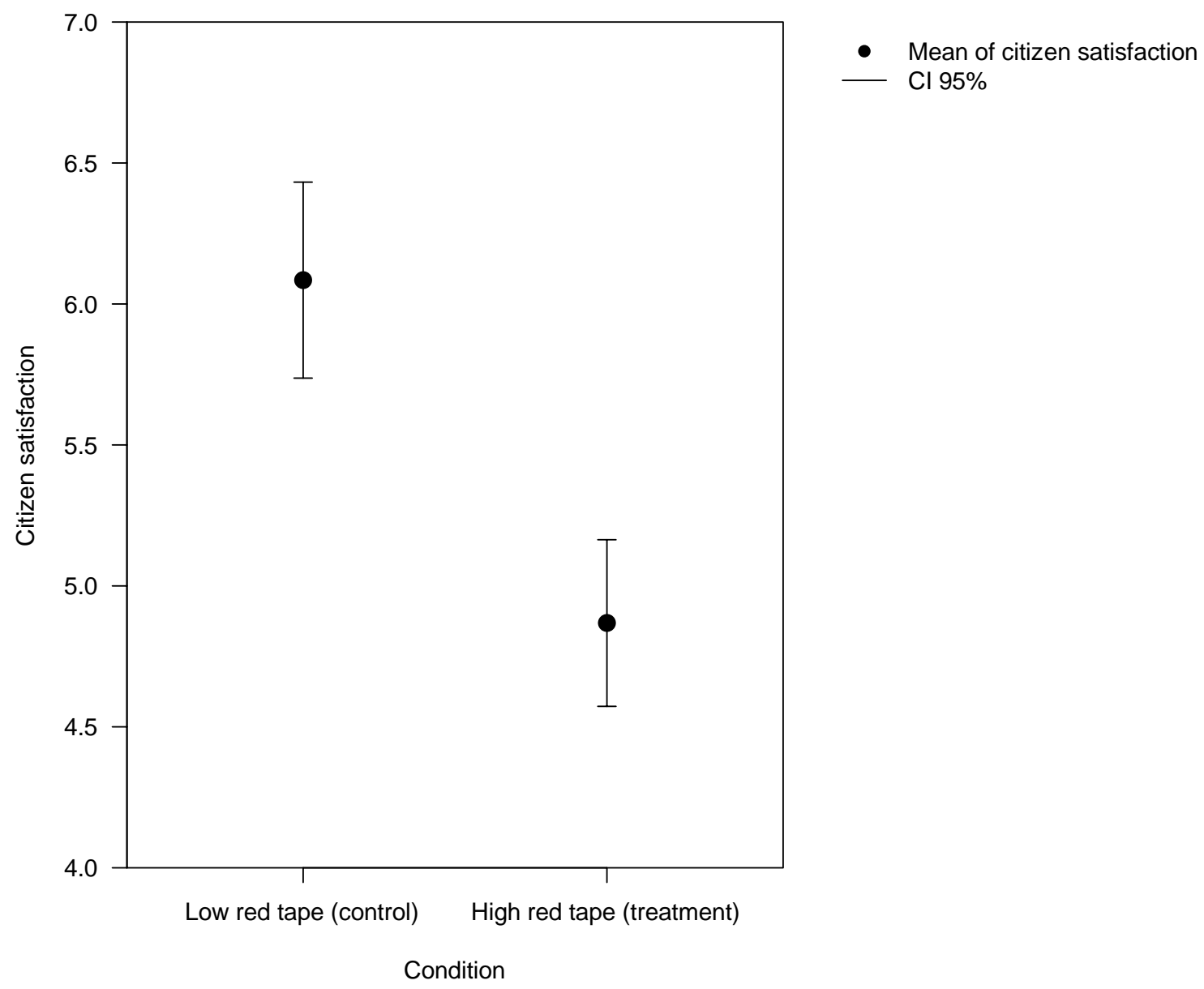

Figure 2 Citizens in high red tape group were less satisfied than citizens in low red tape group

In order to test the moderating effects of knowledge of politics and emotional reactance on the relationship between red tape and citizen satisfaction, four regression analyses were carried out, which are shown in Table 5. 
Table 5 Hierarchical regression analyses for variables predicting citizen satisfaction with governmental services.

\begin{tabular}{|c|c|c|c|c|}
\hline & $\begin{array}{l}\text { Model 1 - } \\
\text { Control or } \\
\text { treatment }\end{array}$ & $\begin{array}{l}\text { Model 2- } \\
\text { Adding } \\
\text { knowledge of } \\
\text { politics and } \\
\text { emotional } \\
\text { reactance }\end{array}$ & $\begin{array}{l}\text { Model 3- } \\
\text { Adding } \\
\text { interaction } \\
\text { emotional } \\
\text { reactance }\end{array}$ & $\begin{array}{l}\text { Model 4- } \\
\text { Adding } \\
\text { interaction } \\
\text { knowledge of } \\
\text { politics }\end{array}$ \\
\hline Red tape & $-.366 * *$ & $-.372 * *$ & $-.379 * *$ & $-.376 * *$ \\
\hline $\begin{array}{l}\text { Knowledge of } \\
\text { politics }\end{array}$ & - & .110 & .077 & .080 \\
\hline $\begin{array}{l}\text { Emotional } \\
\text { reactance }\end{array}$ & - & $-.171 *$ & $-.165^{*}$ & $-.160 *$ \\
\hline $\begin{array}{l}\text { Red tape \& } \\
\text { Emotional } \\
\text { reactance }\end{array}$ & - & - & -.020 & - \\
\hline $\begin{array}{l}\text { Red tape \& } \\
\text { Knowledge of } \\
\text { politics }\end{array}$ & - & - & - & $.137^{*}$ \\
\hline Adjusted $\mathrm{R}^{2}$ & $.129 * *$ & $.149 * *$ & $144^{* *}$ & $.163 * *$ \\
\hline \multicolumn{5}{|c|}{$\begin{array}{l}\text { Note: Standardized beta coefficients are presented. } * \mathrm{p}<.05 * * \mathrm{p}<.01 \text {. } \\
\text { The following criteria are met (based on Field 2009). For final model: } \\
\text { Criterion of independent residuals (Durbin-Watson } 1.537,1<\text { criterion }<3 \text { ). Criterion of no } \\
\text { multicollinearity (No VIF values above } 10 \text { and average close to } 1 \text { ). No exclusion of } \\
\text { influential outlying cases was required (using casewise diagnostics: } 3.977 \% \text { above } \\
\text { standardized residual }>|2| \text {, Cook's distance max. } 0.133 \text { (criterion }<1 \text { ). Criteria of } \\
\text { homoscedasticity and normality met. }\end{array}$} \\
\hline
\end{tabular}


In the first model, we analyzed the relationship between red tape (control=0 or treatment=1) and citizen satisfaction. In the subsequent models, we added knowledge of politics and emotional reactance (model 2) and the interaction effects of emotional reactance with red tape (model 3) and knowledge of politics with red tape (model 4). In each step, the adjusted $\mathrm{R}^{2}$ is calculated, and we determine which model explains the most variance (adjusted for the number of variables). In the first model, with only red tape in the equation, the adjusted $\mathrm{R}^{2}$ was .129. Adding knowledge of politics and emotional reactance in the second model increased the adjusted $\mathrm{R}^{2}$ to .149 . However, when inserting the interaction variable of emotional reactance with red tape, the adjusted $R^{2}$ was reduced to .144 . Hence, this interaction did not add value to explaining citizen satisfaction. In order to keep the model parsimonious, the emotional reactance interaction was dropped when including the interaction of knowledge of politics in the final model. This model had the highest adjusted $\mathrm{R}^{2}$, namely .163 . Note that including the interaction of emotional reactance in this model led to a decrease in the $\mathrm{R}^{2}$. Concluding, Model 4 worked best for our data and was used.

The first hypothesis states that red tape has a negative effect on citizen satisfaction. The results indicate that this is indeed the case. Furthermore, the effect is quite strong, with a standardized beta of .38 .

The second hypothesis states that the impact of red tape on citizen satisfaction is weaker for people with high-perceived knowledge. The results indicate that the interaction effect is indeed present $(\beta=.137, \mathrm{p}<.05) .{ }^{1}$ This is shown in Figure 3 . It can be 


\section{RED TAPE AND CITIZEN SATISFACTION}

seen that in the low red tape situation, both people who have a high knowledge of politics and those with low knowledge are quite satisfied. In the high red tape situation, both are less satisfied. However, people having low knowledge become increasingly dissatisfied when confronted with red tape: their line drops far quicker than for people with low knowledge of politics. This means hypothesis 2 is supported by the data.

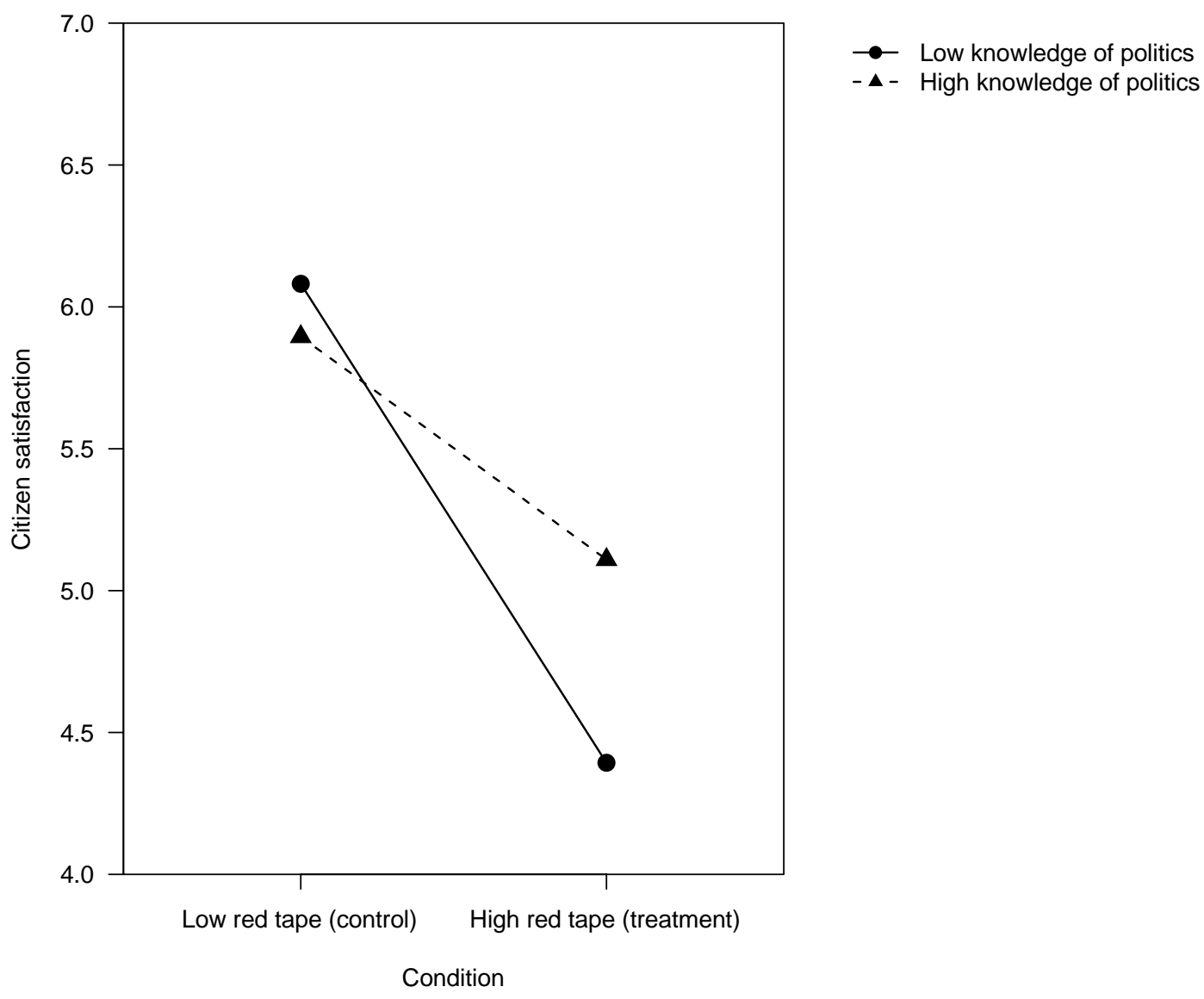

Figure 3 Interaction effect of red tape and knowledge of politics on citizen satisfaction. No main effect present. 


\section{RED TAPE AND CITIZEN SATISFACTION}

Lastly, hypothesis three argued that the effect of red tape on citizen satisfaction is strongest for people scoring high on emotional reactance. However, we did not find a significant interaction effect $(\beta=-.020, \mathrm{p}>.05)$. This is shown in Figure 4. For both people with low and high emotional reactance, citizen satisfaction is lower when confronted with high red tape. This means hypothesis three is rejected. On the other hand, we found a direct effect, also shown in Figure $4(\beta=-.160, \mathrm{p}<.05)$. People with high emotional reactance tend to be more dissatisfied overall than those with low emotional reactance. Hence, there is only a direct effect but no interaction effect: red tape remains equally negative across both low and high reactance groups. 


\section{RED TAPE AND CITIZEN SATISFACTION}

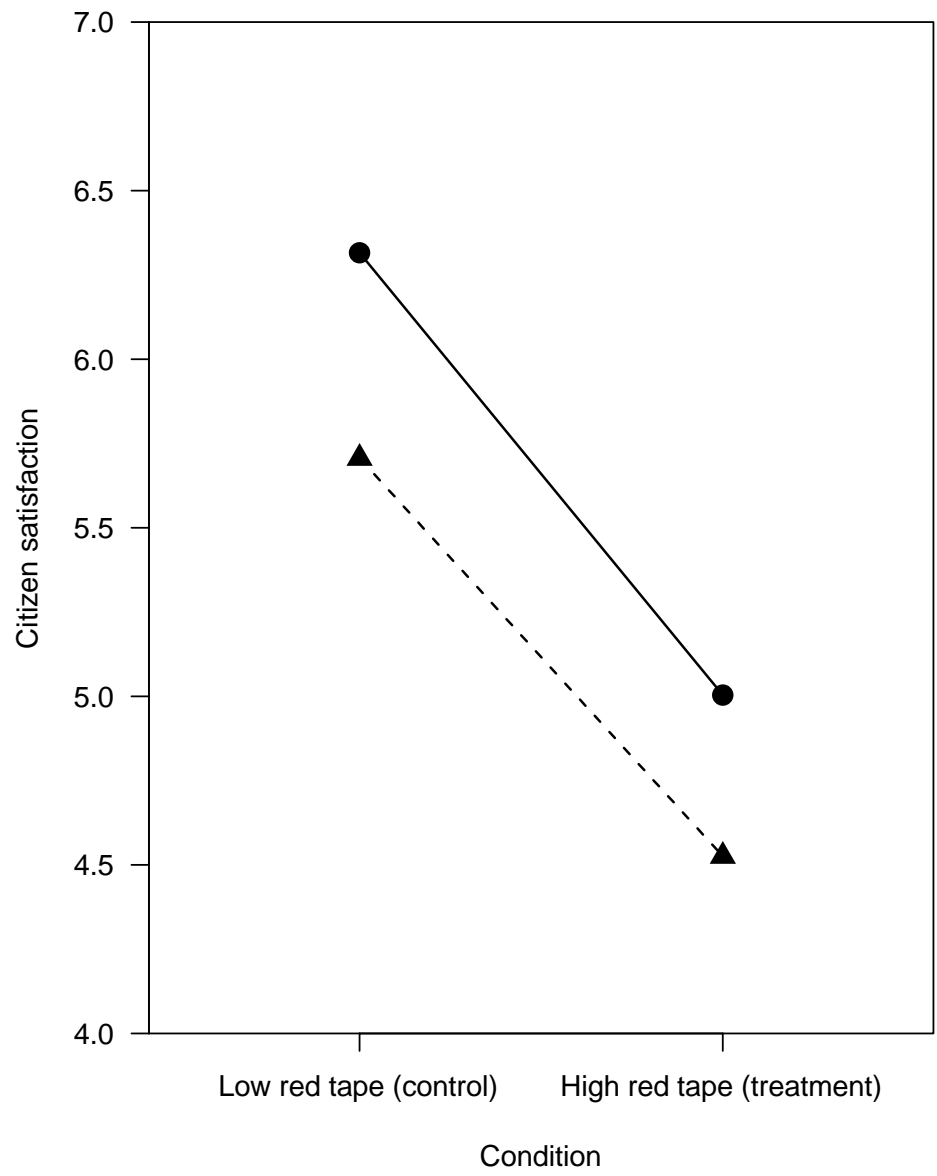

$\longrightarrow$ Low Emotional Reactance

- $\Delta$ - High Emotional Reactance

Figure 4 High emotional reactance is related to less satisfaction in both control and treatment. No interaction effect present.

\section{CONCLUSION AND DISCUSSION}

This study has added two important elements to the red tape literature. First, it is one of the few looking at the effect red tape for citizens. Second, we used experimentation as a way to determine whether the assumed negative relationship between red tape and satisfaction is indeed a causal relation. In this final section, we discuss the conclusions 
that can be drawn from this study, as well as some limitations and related future research suggestions.

We firstly found that red tape indeed negatively affects citizen satisfaction. This is an important finding, as it seems to contradict a study by Brewer and Walker (2010), who showed that red tape is not related to citizen satisfaction in English local government. A possible explanation for this difference is that their measurement of red tape was different. They measured red tape by asking managers about the general degree of red tape for various stakeholders, while we analyzed the effect of red tape on actual citizen perceptions. On the other hand, a survey by Townsend and Kosloski (2002) did found a relationship. In addition to these mixed findings, both studies rely on results from a cross-sectional survey, which suffers from endogeneity problems (reverse-causality, omitted variable bias, or selection bias). When testing for causal effects, few of the methods in the social sciences can live up to the rigor and level of control of an experimental design.

Secondly, an important finding from this study is that the effect of red tape is weakened when people have high knowledge of politics. This means that knowledge can buffer red tape effects on citizen satisfaction. This finding resonates with other experimental research in public administration on how knowledge mitigates effects of transparency on trust in government (Grimmelikhuijsen and Meijer 2014). This is also consistent with theories from social psychology about the way people process information (Petty and Cacioppo 1986). It indeed seems that people with high knowledge process information differently and as a consequence have a different assessment of what 
is going on in government and political organizations (Mondak et al. 2007). However, this result should be interpreted with some caution, since the variable "knowledge of politics" was measured using a subjective scale, and this might be quite different from the objective knowledge of the participants. Future studies could reanalyze the model using an objective scale to whether it yields the same results.

Future research could take this one step further by analyzing which potential interventions can be conducted to lower the degree of perceived red tape. For instance, does communicating about the goal of the rule also diminish the degree of experienced red tape? Garnett, Marlowe and Pandey (2008) showed that communication can ameliorate the perceived performance of an organization, as long as an organizational culture is not too much restricted by red tape. Additionally, scholars can analyze the model we have developed here using the notion of "multidimensional red tape" recently developed by Bozeman (2012). Bozeman notes that the core idea of multidimensional red tape is that is pathological in some aspects and beneficial in others, even for one stakeholder. Related to this it recognizes that stakeholders can assess rules based on different objectives to be reached. Based on this, scholars could for instance analyze to what extent certain rules reach different objectives (such as increased citizen satisfaction or increased trust in government), and the tradeoffs among reaching those objectives. Contrary to this, we only analyzed one potential objective (citizen satisfaction).

Furthermore, we found that emotional reactance was not a significant moderator in the relation between red tape and satisfaction. One possible explanation for the insignificant moderating effect is that the level of red tape - even in the control group - 
was already above the acceptable threshold for people scoring high on emotional reactance. People high in emotional reactance could feel that their freedom is already restricted even if they have to fill out a short form. This fits with more general psychological research, which shows that people high in emotional reactance are more prone to resist stimuli (Taut and Brauns 2003; Brehm and Brehm 1981). Elaborating on this, and related insights of the influence of personality characteristics influencing job satisfaction (Judge and Larsen 2001), we note that there is a real possibility that citizen satisfaction is partly determined by personality characteristics of citizens. More generally, it seems that taking into account personality characteristics of citizens and other stakeholders can be a fruitful approach for public administration scholars. This fits with an increased emphasis on using psychological theories to answer important questions in public administration (Tummers 2013,; Grimmelikhuijsen and Meijer 2014,; Stritch and Christensen 2013).

What can governments learn from these results? The most straightforward conclusion is that reducing red tape seems to pay off in terms of satisfaction. Second, if elaborate rules are somehow necessary, it may help to educate citizens about government and political processes in order to help them understand why burdensome rules are sometimes necessary and why unnecessary rules sometimes emanate from the bureaucracy. Even though people with high knowledge still respond negatively to red tape, this knowledge clearly mitigates the negative effect.

We should discuss an important limitation of this study. We used a nonrepresentative sample (students) to assess the effect of red tape on citizen satisfaction. 


\section{RED TAPE AND CITIZEN SATISFACTION}

Although a student sample for experimentation has the advantage of homogeneity between experiment groups and as a result increasing internal validity, we acknowledge that other samples may yield different results. Future research could check the insights gained here using different kinds of participants, for example those who are more representative for the total population of citizens or those with lower levels of knowledge about politics and government processes.

To the best of our knowledge, this is one of the only scholarly studies that has focused on the effect of red tape on citizen perceptions. More future research is needed in this area to analyze how citizens respond to red tape. The lack of scholarly studies is surprising, given the importance of citizen perceptions and the taken-for-granted assumption that red tape negatively affects how citizens feel about government. We investigated this assumption by focusing on a hypothetical passport application procedure. However, it is also necessary to explore what real-life experiences citizens have with red tape and how this affects their perceptions of government organizations. An in-depth analysis using field experiments can be very valuable to improve our understanding on how red tape influences citizen perceptions in real-life situations, and how government can develop interventions to improve service delivery.

\section{NOTES}

${ }^{1}$ Note that in a model with both interactions (which is a poorer fit of the data than our final model 4) indicate that the interaction between knowledge of politics with red tape was also present, but with an alpha level just above $.05(\beta=-.138, \mathrm{p}=.052)$. The alpha 
level is only slightly above the common threshold of .05. Although technically we should disregard this results as non-significant, we feel that this is inappropriate as it is caused by the inclusion of an insignificant interaction of emotional reactance and red tape. More importantly, the model was also less suitable for our data, shown by the lower explained variance. Hence, including the interaction of emotional reactance and red tape resulted in a less fitting model and the interaction with knowledge of politics it is only .002 above the common threshold of .05 , thereby possibly leading to a Type I error.

\section{REFERENCES}

Baethge C.; Blom-Hansen J.; Bækgraad M.; Dunlop C.; Esteve M.; Jakobsen M.; Kisidia B.; Marvel J.; Moseley A.; Serritzlew S.; Steward P.; Thomsen M.; and Wolf P. (2015). Conducting Experiments in Public Management Research: A Practical Guide. International Public Management Journal.

Boardman, C., B. Bozeman and B. Ponomariov. 2010. "Private Sector Imprinting: An Examination of the Impacts of Private Sector Job Experience on Public Manager's Work Attitudes." Public Administration Review 70(1): 50-59.

Bohner, G. 2001. "Attitudes.” Pp. 239-282 in M. Hewstone and W. Stroebe, ed., In Introduction to Social Psychology: A European Perspective, Malden, MA: Blackwell Publishing.

Bouckaert, G. and S. Van de Walle. 2003. "Comparing Measures of Citizen Trust and User Satisfaction as Indicators of 'Good Governance': Difficulties in Linking Trust and Satisfaction Indicators." International Review of Administrative Sciences 69(3): 329-343.

Bozeman, B. 1993. "A Theory of Government 'Red Tape'." Journal of Public Administration Research and Theory 3(3): 273-304.

Bozeman, B. 2000. Bureaucracy and Red Tape. Upper Saddle River, NJ: Prentice Hall. Bozeman, B. 2012. "Multidimensional Red Tape: A Theory Coda." International Public Management Journal 15(3): 245-265.

Bozeman, B. and M. K. Feeney. 2011. Rules and Red Tape: A Prism for Public Administration Theory and Research. London: M.E. Sharpe.

Bozeman, B. and G. Kingsley. 1998. "Risk Culture in Public and Private Organizations." Public Administration Review 58(2): 109-118.

Brehm, S. S. and J. W. Brehm. 1981. Psychological Reactance: A Theory of Freedom and Control. New York: Academic Press. 
Brewer, G. A. and S. C. Selden. 2000. "Why Elephants Gallop: Assessing and Predicting Organizational Performance in Federal Agencies." Journal of Public Administration Research and Theory 10(4): 685-712.

Brewer, G. A. and R. M. Walker. 2010a. "Explaining Variation in Perceptions of Red Tape: A Professionalism-Marketization Model.” Public Administration 88(2): 418-438.

Brewer, G. A. and R. M. Walker. 2010b. "The Impact of Red Tape on Governmental Performance: An Empirical Analysis." Journal of Public Administration Research and Theory 20(1): 233-257.

Calder, B. J., L. W. Phillips and A. M. Tybout. 1982. "The Concept of External Validity." Journal of Consumer Research 9(3): 240-244.

Chen, C. A. 2011. "Sector Imprinting: Exploring its Impacts on Managers' Perceived Formalized Personnel Rules, Perceived Red Tape, and Current Job Tenure." The American Review of Public Administration XX(X): 1-21.

DeHart-Davis, L. 2009. "Green Tape: A Theory of Effective Organizational Rules." Journal of Public Administration Research and Theory 19(2): 361-384.

DeHart-Davis, L., J. Chen and T. D. Little. 2013. "Written Versus Unwritten Rules: The Role of Rule Formalization in Green Tape." International Public Management Journal 16(3): 331-356.

DeHart-Davis, L., R. S. Davis and Z. Mohr. 2014. "Green Tape and Job Satisfaction: Can Organizational Rules Make Employees Happy?” Journal of Public Administration Research and Theory doi: 10.1093/jopart/muu038

DeHart-Davis, L. and S. K. Pandey. 2005. "Red Tape and Public Employees: Does Perceived Rule Dysfunction Alienate Managers?" Journal of Public Administration Research and Theory 15(1): 133-148.

Dowd, E. T. and F. Wallbrown. 1993. "Motivational Components of Client Reactance." Journal of Counseling and Development 71(5): 533-538.

Easton, D. 1975. "A re-assessment of the concept of political support." British Journal of Political Science 5(4): 435-457.

Feeney, M. K. and L. DeHart-Davis. 2009. "Bureaucracy and Public Employee Behavior: A Case of Local Government." Review of Public Personnel Administration 29(4): 311-326.

Field, A. 2009. Discovering statistics using IBM SPSS statistics. London: Sage Publications.

Garnett, J. L., J. Marlowe and S. K. Pandey. 2008. "Penetrating the Performance Predicament: Communication as a Mediator or Moderator of Organizational Culture's Impact on Public Organizational Performance." Public Administration Review 68(2): 266-281.

Giauque, D., A. Ritz, F. Varone and S. Anderfuhren-Biget. 2012. "Resigned but Satisfied: The Negative Impact of Public Service Motivation and Red Tape on Work Satisfaction." Public Administration 90(1): 175-193.

Gore, A. 1993. From Red Tape to Results: Creating a Government that Works Better and Costs Less. Report of the National Performance Review. DIANE Publishing. 
Grimmelikhuijsen, S. G. 2011. "Being Transparent or Spinning the Message? An Experiment Into the Effects of Varying Message Content on Trust in Government." Information Polity 16(1): 35-50.

Grimmelikhuijsen, S. G. and A. J. Meijer. 2014. "The Effects of Transparency on the Perceived Trustworthiness of a Government Organization: Evidence from an Online Experiment." Journal of Public Administration Theory and Research 24(1): 137-157.

Holt, D. T., A. A. Armenakis, H. S. Field and S. G. Harris. 2007. "Readiness for Organizational Change: The Systematic Development of a Scale." The Journal of Applied Behavioral Science 43(2): 232-255.

Hong, S.M. and S. Page. 1989. "A Psychological Reactance Scale: Development, Factor Structure and Reliability." Psychological Reports 64(3c): 1323-1326.

James, O. 2009. "Evaluating the Expectations Disconfirmation and Expectations Anchoring Approaches to Citizen Satisfaction with Local Public Services." Journal of Public Administration Research and Theory 19(1): 107-123.

Judge, T. A. and R. J. Larsen. 2001. "Dispositional affect and job satisfaction: A review and theoretical extension." Organizational Behavior and Human Decision Processes 86(1): 67-98.

Kaufman, H. 1977. Red Tape: Its Origins, Uses, and Abuses. Washington, DC: Brookings Institution.

Kaufmann, W. and M. K. Feeney. 2014. "Beyond the Rules: The Effect of Outcome Favourability on Red Tape Perceptions." Public Administration 92(1): 178-191.

Kusow, A. M., L. C. Wilson and D. E. Martin. 1997. "Determinants of Citizen Satisfaction with the Police: The Effects of Residential Location." Policing: An International Journal of Police Strategies and Management 20(4): 655-664.

Margetts, H. Z. 2011. "Experiments for Public Management Research." Public Management Review 13(2): 189-208.

Mintz, A., S. B. Redd and A. Vedlitz. 2006. "Can we Generalize from Student Experiments to the Real World in Political Science, Military Affairs, and International Relations?" Journal of Conflict Resolution 50(5): 757-776.

Mondak, J. J., E. G. Carmines, R. Huckfeldt, D. Mitchell and S. Schraufnagel. 2007. "Does Familiarity Breed Contempt? The Impact of Information on Mass Attitudes Toward Congress." American Journal of Political Science 51(1): 34-48.

Moon, M. J. and S. Bretschneider. 2002. "Does the Perception of Red Tape Constrain IT Innovativeness in Organizations? Unexpected Results from a Simultaneous Equation Model and Implications." Journal of Public Administration Research and Theory 12(2): 273-292.

Morton, R. B. and K. C. Williams. 2010. Experimental Political Science and the Study of Causality. New York: Cambridge University Press.

Moynihan, D. P., B. E. Wright and S. K. Pandey. 2012. "Working Within Constraints: Can Transformational Leaders Alter the Experience of Red Tape?" International Public Management Journal 15(3): 315-336. 
Moynihan, D., P. Herd and H. Harvey. 2014. “Administrative Burden: Learning, Psychological, and Compliance Costs in Citizen-State Interactions." Journal of Public Administration Research and Theory doi: 10.1093/jopart/muu009.

Pandey, S. K., D. H. Coursey and D. P. Moynihan. 2007. "Organizational Effectiveness and Bureaucratic Red Tape: A Multimethod Study." Public Performance and Management Review 30(3): 398-425.

Pandey, S. K. and G. A. Kingsley. 2000. "Examining Red Tape in Public and Private Organizations: Alternative Explanations from a Social Psychological Model." Journal of Public Administration Research and Theory 10(4): 779-800.

Pandey, S. K. and J. Marlowe. 2014. "Assessing Survey-Based Measurement of Personnel Red Tape With Anchoring Vignettes.” Review of Public Personnel Administration, doi: 10.1177/0734371X14531988.

Pandey, S. K., and P. G. Scott. 2002. "Red tape: A review and assessment of concepts and measures." Journal of Public Administration Research and Theory 12(4): 553-580.

Pandey, S. K. and E. W. Welch. 2005. "Beyond Stereotypes A Multistage Model of Managerial Perceptions of Red Tape.” Administration \& Society 37(5): 542-575.

Petty, R. E. and J. T. Cacioppo. 1986. "The Elaboration Likelihood Model of Persuasion." Pp.1-24 in R. E. Petty and J. T. Cacioppo, ed., Communication and Persuasion. New York: Springer.

Pollitt, C. and G. Bouckaert. 2004. Public Management Reform: A comparative Analysis. Oxford: Oxford University Press.

Ponomariov, B. L. and P. C. Boardman. 2011. "Organizational pathology compared to what? Impacts of job characteristics and career trajectory on perceptions of organizational red tape." Public Administration Review 71(4): 582-597.

Pugh, D. S., D. J. Hickson and C. R. Hinings. 1969. "An empirical taxonomy of structures of work organizations." Administrative Science Quarterly 14(1): 115126.

Rainey, H. G., S. Pandey and B. Bozeman. 1995. "Research note: Public and private managers' perceptions of red tape,"” Public Administration Review 55(6): 567-574.

Scott, P. G. and S. K. Pandey. 2000. "The Influence of Red Tape on Bureaucratic Behavior: An Experimental Simulation." Journal of Policy Analysis and Management 19(4): 615-633.

Scott, P. G. and S. K. Pandey. 2005. "Red Tape and Public Service Motivation: Findings from a National Survey of Managers in State Health and Human Services Agencies." Review of Public Personnel Administration 25(2): 155-180.

Shen, L. and J. P. Dillard. 2005. "Psychometric Properties of the Hong Psychological Reactance Scale." Journal of Personality Assessment 85(1): 74-81.

Stazyk, E. C., S. K. Pandey and B. E. Wright. 2011. "Understanding Affective Organizational Commitment: The Importance of Institutional Context." The American Review of Public Administration 41(6): 603-624.

Stritch, J. M. and R. K. Christensen. 2013. "Looking at a Job's Social Impact Through PSM-Tinted Lenses: Probing the Motivation-Perception Relationship." Public Administration (Early View). 
Taut, S. and D. Brauns. 2003. "Resistance to evaluation a psychological perspective." Evaluation 9(3): 247-264.

Townsend, D. and K. Kosloski. 2002. "Factors Related to Client Satisfaction with Community-Based Respite Services." Home Health Care Services Quarterly 21(3-4): 89-106.

Tummers, L. G. 2013. Policy alienation and the power of professionals: Confronting new policies. Edward Elgar Publishing.

Tummers, L. G., A. J. Steijn and V. J. J. J. M. Bekkers. 2012. "Explaining the Willingness of Public Professionals to Implement Public Policies: Content, Context, and Personality Characteristics." Public Administration 90(3): 716-736.

Van Ryzin, G. G. 2004. "Expectations, Performance, and Citizen Satisfaction with Urban Services." Journal of Policy Analysis and Management 23: 433-448.

Van Ryzin, G. G. 2006. "Testing the Expectancy Disconfirmation Model of Citizen Satisfaction with Local Government." Journal of Public Administration Research and Theory 16(4): 599-611.

Van Ryzin, G. G., D. Muzzio, S. Immerwahr, L. Gulick and E. Martinez. 2004. "Drivers and Consequences of Citizen Satisfaction: An Application of the American Customer Satisfaction Index Model to New York City." Public Administration Review 64: 321-341.

Vigoda, E. 2002. "From responsiveness to collaboration: Governance, citizens, and the next generation of public administration." Public Administration Review 62(5): 527-540.

Waldo, D. 1964. "Government by Procedure." Pp. 381-399 in F. M. Marx, ed., Elements of Public Administration. Englewood Cliffs, NJ: Prentice-Hall.

Walker, R. M. and G. A. Brewer. 2008. "An Organizational Echelon Analysis of the Determinants of Red Tape in Public Organizations." Public Administration Review 68: 1112-1127. 